\title{
The Roles of NDR Protein Kinases in Hippo Signalling
}

\author{
Alexander Hergovich \\ Cancer Institute, University College London, Paul O'Gorman building, 72 Huntley Street, London WC1E 6BT, \\ UK; a.hergovich@ucl.ac.uk; Tel.: +44-20-7679-0723; Fax: +44-20-7679-6817
}

Academic Editor: Paul Reynolds

Received: 19 April 2016; Accepted: 10 May 2016; Published: 18 May 2016

\begin{abstract}
The Hippo tumour suppressor pathway has emerged as a critical regulator of tissue growth through controlling cellular processes such as cell proliferation, death, differentiation and stemness. Traditionally, the core cassette of the Hippo pathway includes the MST1/2 protein kinases, the LATS1/2 protein kinases, and the MOB1 scaffold signal transducer, which together regulate the transcriptional co-activator functions of the proto-oncoproteins YAP and TAZ through LATS1/2-mediated phosphorylation of YAP/TAZ. Recent research has identified additional kinases, such as NDR1/2 (also known as STK38/STK38L) and MAP4Ks, which should be considered as novel members of the Hippo core cassette. While these efforts helped to expand our understanding of Hippo core signalling, they also began to provide insights into the complexity and redundancy of the Hippo signalling network. Here, we focus on summarising our current knowledge of the regulation and functions of mammalian NDR kinases, discussing parallels between the NDR pathways in Drosophila and mammals. Initially, we provide a general overview of the cellular functions of NDR kinases in cell cycle progression, centrosome biology, apoptosis, autophagy, DNA damage signalling, immunology and neurobiology. Finally, we put particular emphasis on discussing NDR1/2 as YAP kinases downstream of MST1/2 and MOB1 signalling in Hippo signalling.
\end{abstract}

Keywords: NDR; Nuclear Dbf2-related kinase; STK38; serine/threonine kinase 38; LATS; large tumour suppressor; Warts kinase; Hippo kinase signalling; Tricornered; Yes-associated protein

\section{Introduction}

More than a decade ago the Hippo pathway was discovered as a highly conserved signal transduction cascade that functions as a key co-ordinator of tissue growth control and homeostasis $[1,2]$. From a classical perspective, the core cassette of the mammalian Hippo pathway comprises the following signal transducers: the Ste20-like serine/threonine protein kinases MST1 and MST2 (also termed STK4 and STK3), the AGC serine/threonine protein kinases LATS1 and LATS2, and the SAV1 (also termed WW45) and MOB1 scaffold proteins [1,3]; with the transcriptional co-activators YAP and TAZ functioning as major effectors of Hippo signalling [4,5]. In its on-state, the Hippo pathway inhibits YAP/TAZ by MST1/2-SAV1-MOB1-LATS1/2 signalling through LATS1/2-mediated phosphorylation of YAP/TAZ on different serine residues, which can cause cytoplasmic retention and proteasome-mediated degradation of YAP/TAZ [6]. Once the Hippo pathway is turned off, MST1/2 do not activate LATS1/2, hence resulting in the release of YAP/TAZ from inhibitory phosphorylation events by LATS1/2, and subsequently in the nuclear accumulation of active YAP/TAZ. While this model of a linear signalling cascade served well for the initial studies of the Hippo pathway, recent research has uncovered additional kinases, such as the AGC serine/threonine NDR1/2 kinases (also known as STK38/STK38L) and members of the Ste20-like MAP4K family, as novel members of the core cassette of Hippo signalling (Figure 1). More specifically, together with MST1/2 various members of the MAP4K kinase family are responsible for the activating phosphorylation of LATS1/2 in order to 
inhibit YAP/TAZ through LATS1/2-mediated phosphorylation [7-9]. In addition, although LATS1/2 are the important YAP kinases in HEK293 cells [7], a recent study by Zhang et al. established NDR1/2 as additional YAP kinases using a combination of biochemical, cell biological and genetic approaches [10]. Cumulatively, these recent studies helped to expand our understanding of Hippo core signalling by providing insights into the complexity of the Hippo core cassette functioning upstream of YAP/TAZ (Figure 1). In this review, we will focus on summarising the connections of the NDR1/2 protein kinases with the Hippo pathway and provide an updated overview of cellular functions and substrates of NDR1/2.

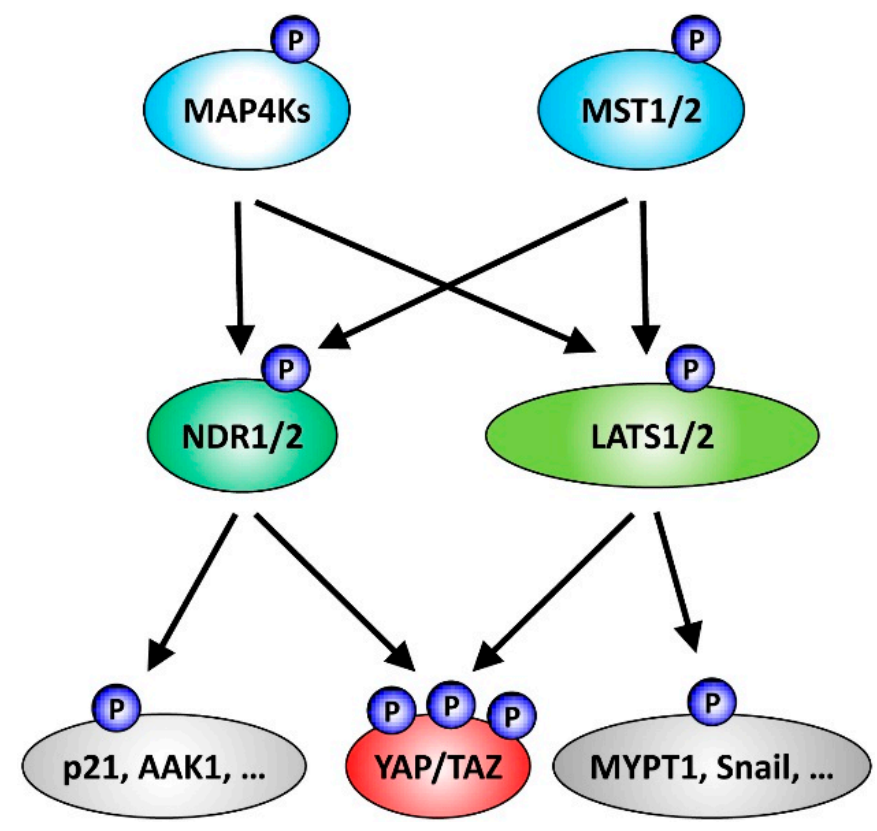

Figure 1. Summary of NDR/LATS kinase signalling functioning downstream of Ste20-like kinases and upstream of the Hippo effectors YAP/TAZ. Classically, the core cassette of the mammalian Hippo pathway includes the Ste20-like serine/threonine protein kinases MST1/2 and the AGC serine/threonine protein kinases LATS1/2. Active MST1/2-LATS1/2 signalling through LATS1/2-mediated phosphorylation of YAP/TAZ can inhibit the transcriptional co-activators YAP and TAZ, two major effectors of Hippo signalling. However, the list of kinases functioning as part of the Hippo core cassette has been expanded recently. In addition to MST1/2, members of the Ste20-like MAP4K kinase family can perform the activating phosphorylation of LATS1/2, consequently resulting in YAP/TAZ inhibition through LATS1/2-mediated phosphorylation. Moreover, the AGC serine/threonine NDR1/2 kinases can act as YAP kinases. Noteworthy, as outlined in more detail in the main text, MAP4K4 can also function upstream of NDR1/2, and NDR1/2 as well as LATS1/2 kinases phosphorylate additional substrates besides YAP.

\section{Review}

The first NDR serine/threonine kinase, termed Dbf2p, was discovered in budding yeast [11], followed by discoveries in Neurospora crassa [12] and human cells [13], while Tricornered (Trc), the fly counterpart of mammalian NDR1 and NDR2 kinases, was identified later [14]. Noteworthy, members of the NDR kinase family are so highly conserved that human NDR1 can rescue the loss-of-function phenotype of Trc-deficient flies [3,15]. Based on unique structural characteristics members of the NDR kinase family have been identified in diverse eukaryotes ranging from unicellular organisms such as yeast to complex multicellular organisms such as plants, animals and humans [3]. In this regard, one should note that NDR kinases are essential for the survival of many uni- and multicellular organisms. For example, NDR kinases are required for the viability of Trypanosoma brucei, the causative 
agent of human African trypanosomiasis [16], and genetic inactivation of Trc, the fly NDR kinase, results in larval lethality [14]. Furthermore, Ndr1/2 double knockout mouse embryos display multiple phenotypes including defective somitogenesis and cardiac looping, resulting in a developmental delay from embryonic Day 8.5 (E8.5) onwards, followed by embryonic lethality around E10 [17]. Therefore, it is important to understand the molecular and cellular functions of NDR kinases in different species.

\subsection{The Regulation of Mammalian NDR1/2 Kinases}

Initially, little was known about the in vivo functions of mammalian NDR1/2 kinases, but extensive biochemical studies have been carried out to understand the molecular regulation of NDR1/2 kinases, which up to recently $[18,19]$ had to serve as a model for the regulation of LATS1/2 kinases [20]. In summary, it was discovered that MST1, MST2 and MST3 can phosphorylate NDR1/2 on Thr444/Thr442 in their hydrophobic motifs, while the binding of MOB1 to NDR1/2 through the highly conserved NTR domain, located proximal to the catalytic domain of NDR1/2, is required to support the auto-phosphorylation of NDR1/2 on Ser281/Ser282 in their T-loop (summarised in $[3,20,21])$. Noteworthy, the experimental activation of NDR1/2 can be achieved through different routes involving the inhibition of protein phosphatase 2A (PP2A) [22], the mutation of an autoinhibitory segment juxtaposed to the T-loop phosphorylation site [23], membrane targeting of NDR1/2 [24], and through modifications of the hydrophobic motif $[25,26]$. Therefore, NDR1/2 can be regulated through different molecular mechanisms involving changes in their subcellular distribution and phosphorylation status (modified by upstream activators such as MST1/2/3 and inhibitors such as PP2A). Nevertheless, NDR1/2 kinases are possibly also regulated by post-translational modifications other than phosphorylation, including ISGylation of NDR1 [27] and ubiquitination and acetylation of NDR1/2 as proposed by the Cell Signaling database (www.phosphosite.org). However, the functional significance of these additional post-translational modifications is yet to be established.

\subsection{Biological Functions of Mammalian NDR1/2 Kinases}

\subsubsection{Roles of NDR1/2 in Cell Cycle Progression and Cell Cycle Associated Processes}

Experiments using tissue culture cells indicate that NDR1/2 can play diverse roles in processes associated with the mammalian cell cycle. Through the regulation of c-myc and p21/Cip1 protein levels, NDR1/2 have been linked to the regulation of G1/S cell cycle progression [28-31], with p21/Cip1 as NDR1/2 substrate (Tables 1 and 2). NDR1/2-mediated G1/S cell cycle progression is supported by cyclin D1 [32] and can oppose a TGF $\beta$-mediated cell cycle arrest [33]. NDR1 can further play a role in mitosis $[34,35]$ through NDR1/2-mediated phosphorylation of heterochromatin protein $1 \alpha$ (HP1 $\alpha$, also known as CBX5) [36] (Tables 1 and 2) and NDR1 functioning downstream of PLK1 in mitotic cells [37]. In addition, the cell cycle dependent localisation of NDR1/2 to centrosomes [38] can support centrosome duplication in S-phase [26,38,39]. Moreover, NDR2-mediated phosphorylation of Rabin8 supports primary cilia formation [40] (Tables 1 and 2), which supports a possible role of defective NDR2 signalling in ciliopathy [41,42], since primary cilia, as cell cycle regulated antenna-like sensory structures with a centrosome base, play important roles in signal transduction $[43,44]$ and disease-associated processes $[45,46]$.

\subsubsection{Roles of NDR1/2 in Apoptosis, Stress Signalling and Autophagy}

Current reports suggest that NDR1/2 can function as pro-apoptotic kinases downstream of Ste20-like kinases [47-52], with MICAL-1 interfering with MST1-mediated phosphorylation (activation) of NDR1/2 in apoptotic cells [50,51]. Furthermore, NDR1/2 contribute to stress signalling [49,53] and play a role in autophagy as a major stress response [48]. More specifically, NDR1 and Trc are required for early autophagosome formation in human cells and fly larvae, respectively [48], a process which most likely involves Beclin1 and ULK1 as major regulators of autophagy [54]. In addition, NDR kinases can mediate mitochondrial quality control in flies and human cells [55], suggesting that 
NDR1/2 may sustain selective autophagic processes such as mitophagy. However, the downstream effectors of NDR1/2 in apoptosis and autophagy signalling are yet to be defined.

\subsubsection{Roles of NDR1/2 in DNA Damage Signalling}

By competing with MOB1 for binding to NDR1/2, MOB2 can interfere with NDR1/2 activation [56]. Since MOB2 can function as a DNA damage response (DDR) factor [57], this could suggest that NDR1/2 may also function in the DDR, though this does not seem to be the case, since the DDR role of MOB2 appears to be independent of NDR1/2 signalling [57]. Nevertheless, we believe that only further investigations can completely rule out that NDR1/2 signalling is not linked to the DDR through MOB2, since recent reports already suggest an involvement of NDR1/2 in the DDR. Specifically, NDR1 can interact with XPA (Xeroderma pigmentosum A protein), thereby possibly playing a role in the nucleotide excision repair, a specific type of DNA damage repair [58]. NDR1-depleted HeLa cells displayed increased sensitivity to ionizing radiation [59], which potentially is linked to NDR1 as a HSP90 client $[59,60]$. Moreover, NDR1 appears to be involved in the activation of the DNA damage induced G2/M cell cycle checkpoint by phosphorylating the CDC25A phosphatase on Ser76 [61] (Tables 1 and 2). However, considering that the phosphorylation of CDC25A on Ser76 is also mediated by $\mathrm{CHK} 1$ to promote CDC25A degradation by the SCF ${ }^{\beta}$ TrCP $E 3$ ligase [62], the regulation of the G2/M checkpoint by NDR1/2 deserves further investigation. In this regard, it is already well-established that PLK1 is required for CDC25 activation to initiate the recovery from the G2/M checkpoint [63,64], a process which possibly is linked to the regulation of NDR1/2 by PLK1 [37] and the connection between NDR1/2 and CDC25A [61].

\subsubsection{Roles of NDR1/2 in Immunology}

Initially, it was observed that the HIV-1 virus associates with NDR1/2 [65], however, the biological significance of this interaction remained unknown. Recent studies of mouse models [52,66,67] have started to shed light on the involvement of NDR1/2 in immunological processes, hence suggesting that the association of HIV-1 with NDR1/2 might play a role in the modulation of the immune system by the virus, although this hypothesis is yet to be addressed experimentally. $N d r 1$ knockout mice are prone to develop T cell lymphomas, possibly due to defective apoptotic signalling in T lymphocytes [52]. An independent study of Ndr1 knockout mice further found that NDR1 contributes to the innate immune response of macrophages [66]. In addition, using mice with $\mathrm{T}$ cell specific double knockout of Ndr1/2, Tang et al. found that NDR1/2 play important roles in thymocyte egress and migration [67].

\subsubsection{Roles of NDR1/2 in Neurobiology}

Members of the NDR family play key roles in the morphogenesis of polarised structures in yeast, worms and flies [3], suggesting that NDR kinases may contribute to the biology of highly polarised mammalian cells such as neurons. Initial discoveries of NDR1/2 (Trc) signalling in neuronal development and maintenance were made in flies [68]. It was found that Trc, the fly NDR kinase, is required for dendritic branching and tiling in Drosophila sensory neurons [69], functioning downstream of the Hippo kinase [70] and TORC2 (target of rapamycin complex 2) in dendritic tiling [71]. Subsequently, by employing chemical genetics, Ultanir et al. could demonstrate that NDR1/2 are also important for dendrite growth and spine development in mammals by phosphorylating AAK1 and Rabin8 [72] (Tables 1 and 2). By phosphorylating the polarity protein Par3 (Partitioning defective 3) NDR1/2 can further regulate neuronal polarity [73] (Tables 1 and 2). Moreover, animal studies found that NDR2 plays a role in integrin-dependent neurite outgrowth in mice [74] and that NDR1/2 may act in rat dendrites [75]. 
Table 1. Summary of targeting motifs of NDR1/2 substrates in mammalian cells.

\begin{tabular}{|c|c|}
\hline Targeting motif & Target site \\
\hline$\underline{H} \mathrm{~V} \underline{R} \mathrm{GDpS}$ & YAP1 (human) on Ser61 [10] \\
\hline$\overline{\bar{H}} S \underline{R} Q A p S$ & YAP1 (human) on Ser109 [10] \\
\hline$\underline{\bar{H}} \mathrm{~V} \underline{\mathrm{R}} \mathrm{A} H \mathrm{pS}$ & YAP1 (human) on Ser127 [10] \\
\hline$\underline{H} L Q Q S p S$ & YAP1 (human) on Ser164 [10] \\
\hline$\underline{H} R \underline{R} \underline{I L p S}$ & AAK1 (human) on Ser635 [72] \# \\
\hline$\underline{H} T \underline{R N K \mathrm{pS}}$ & Rabin8 (mouse) on Ser240 [72] \# \\
\hline$\underline{\bar{H}} \mathrm{~T} \underline{\bar{R}} \mathrm{~N} K \mathrm{pS}$ & Rabin8 (human) on Ser272 [40] \\
\hline KRRQTpS & p21/CIP1 (human) on Ser146 [29] \\
\hline $\mathrm{LQ} \underline{\mathrm{R}} \mathrm{MG} \mathrm{S}$ & CDC25A (human) on Ser76 [61] \\
\hline SPGRFpS & Par3 (mouse) on Ser383 [73] \\
\hline QSGRHpS & Par3 (human) on Ser1196 [73] \\
\hline RKSNFpS & HP1 $\alpha$ (human) on Ser95 [36] \#\# \\
\hline$\underline{H} \times \underline{R} X X \mathrm{pS} / \mathrm{T}$ & proposed consensus motif [20] \\
\hline
\end{tabular}

Basic (positively charged) residues are highlighted in italic and present in each motif, although the HXRXXS/T signature is not present in all substrates; \# PI4KB (pSer277), Panx2 (pSer514), and Rab11fip5 (pSer307) sequences are not shown, as they are not confirmed as direct substrates of NDR1/2, although all three substrates match the HXRXXS/T motif [72]; \#\# HP1 $\alpha$ (also termed CBX5) is most likely phosphorylated by NDR1 on additional sites [36].

Table 2. Summary of direct downstream events/substrates of NDR1/2 kinases.

\begin{tabular}{cc}
\hline Substrate & Role of phosphorylation \\
\hline YAP on Ser61 & Not yet determined \\
YAP on Ser109 & Not yet determined \\
YAP on Ser127 & Facilitates cytoplasmic retention [10,76-78] \\
YAP on Ser164 & Not yet determined \\
AAK1 on Ser635 & Dendrite and spine development in neurons [72] \\
Rabin8 on Ser240 & Dendrite and spine development in neurons [72] \\
Rabin8 on Ser272 & Primary cilia formation [40] \\
p21/CIP1 on Ser146 & Regulates p21/CIP1 protein stability [29] \\
CDC25A on Ser76 & Regulates CDC25A protein stability [61]\# \\
Par3 on Ser383 & Regulates neuronal polarity [73] \\
HP1 $\alpha$ on Ser95 & Regulates mitotic progression [36] \\
\hline
\end{tabular}

\# It remains to be clarified whether NDR1-mediated phosphorylation of CDC25A on Ser76 primes the subsequent phosphorylation of CDC25A on Ser79, Ser82 and Ser88 by NEK11, as already reported for CHK1-NEK11 signalling [62,79].

\subsection{The Connections between NDR Kinases and Hippo Core Signalling}

As outlined above, NDR kinases have diverse biological functions, some of which are potentially interlinked with the Hippo pathway. In the following subsections, we provide an overview on how and to which degree fly and mammalian NDR kinases are linked to the core cassette of the Hippo pathway and hence why NDR kinases should be considered as novel core components of Hippo signalling.

\subsubsection{NDR Kinases as YAP Regulators}

In Drosophila, Trc is the counterpart of mammalian NDR1/2 and the Warts kinase corresponds to mammalian LATS1/2, while Yorkie (Yki) and Mats are the orthologues of mammalian YAP/TAZ and MOB1, respectively. Since Trc/Warts double mutant cells displayed additive phenotypes combining the overgrowth phenotype (normally associated with Warts loss-of-function) and the wing hair phenotype (normally associated with Trc mutant), it was proposed that the Tre and Warts pathways function in parallel in fly wing cells [80]. Nevertheless, in spite of these clear differences between the Trc and Warts pathways in fly tissues, there are also connections in some contexts. One connection is that Hippo, the fly MST1/2 kinase, acts upstream of Trc and Warts in fly neurons [70]. A second connection is that Trc and Warts mutant cells display elevated levels of F-actin [80,81], a phenotype also observed 
upon Yki overexpression or Hippo loss-of-function [80]. A third connection is that Trc and Warts mutant cells show upregulated DE-Cadherin expression, which was also observed in Mats mutant cells [80]. Although Yki overexpressing cells displayed multiple hair as well as overgrowth phenotypes as observed in Trc and Warts mutant cells [80], Trc mutant cells did not display altered expression of well-established readouts for Yki activity such as diap1, cyclin E and expanded [80]. Thus, Fang et al. concluded that Trc does not regulate Yki in the fly wing [80], although whether Trc could phosphorylate Yki was not tested.

In mammalian cells, unlike LATS1/2 overexpression, the overexpression of NDR1/2 did not result in a phospho-shift of YAP [82]. Thus, it was believed that NDR1/2 do not function as YAP kinases in mammals [82], but again a possible connection between NDR1/2 and YAP was not further tested biochemically or genetically in this report. Subsequently, Zhang et al. addressed this possible connection experimentally, resulting in the discovery that mammalian NDR1/2 can function as YAP kinases [10]. They found that NDR1/2 directly phosphorylate YAP on Ser61, Ser109, Ser127 and Ser164 (Tables 1 and 2); all four sites being also phosphorylated by LATS1/2 [76,82], hence establishing NDR1/2 as novel bona fide upstream kinases of YAP in vitro. Significantly, NDR1/2-mediated phosphorylation of YAP on Ser127 resulted in the inactivation of YAP by cytoplasmic retention [10], as reported for the LATS1/2-mediated phosphorylation of YAP on Ser127 [76,77], thereby establishing on the cellular level that NDR1/2 can function upstream of YAP. Even more importantly, the genetic ablation of $N d r 1$ and $N d r 2$ in the murine intestinal epithelium resulted in elevated total YAP protein levels accompanied by decreased Ser127 phosphorylation without any alterations in LATS1/2 phosphorylation (either on the T-loop or hydrophobic motifs) and total LATS1/2 protein levels [10]. Significantly, the increased YAP levels in NDR1/2-deficient tissue translated into increased YAP activity in vivo as judged by nuclear accumulation of YAP and elevated YAP target gene expression [10]. Moreover, the concomitant ablation of Yap in Ndr1/2 double knockout tissue resulted in decreased tumour incidences upon chemically-induced colon carcinogenesis [10], suggesting that NDR1/2 are required to restrict the oncogenic potential of YAP in the intestinal epithelium. Taken together, this study [10] established NDR1/2 as novel YAP kinases.

Considering that the regulation of YAP by LATS1/2 has also been established on the biochemical, cellular and organismal levels [76,77,82,83], it is now imperative to establish in which context and settings LATS1/2 and/or NDR1/2 function as YAP kinases. Studies employing mouse genetics have so far shown that NDR1/2 are YAP kinases in the intestine [10] and that LATS1/2 can act as YAP kinases in the liver [83], hence many more studies using mouse models are warranted to investigate the potentially tissue specific roles of NDR1/2 and LATS1/2, both during normal growth and tissue homeostasis, and in tumourigenesis. In this context, it will be very interesting to understand how NDR1/2 can regulate total YAP protein levels without phosphorylating YAP on its phospho-degron motif (Ser381/397 in human cells and Ser366 in mice). Equally important will be to expand to studies of mammalian Lats1/2 and $N d r 1 / 2$ knockout cell lines. Currently we know that Ser127 phosphorylation of YAP is abolished, while total YAP phosphorylation still occurs to a significant extent in Lats1/2 double knockout mouse embryonic fibroblasts [84]. In human Lats1/2 double knockout HEK293 cells Ser127 and total YAP phosphorylation is dramatically diminished in different tissue culture conditions [7], which lead to the suggestion that LATS1/2 are the major YAP kinases [6]. However, we would like to stress that much more work in different cellular and organismal systems will be required to conclusively draw conclusions about the relative contributions of LATS1/2- and/or NDR1/2-mediated phosphorylation of YAP. In this regard, it will also be important to define any possible link between NDR1/2 and the regulation of TAZ, since NDR2, like LATS2 and MOB1B, is a target of the oncogenic microRNA-135b, which can play a role in TAZ deregulation and lung cancer progression [85]. In other words, decreased NDR2 levels have been associated with increased TAZ activity [85], but whether NDR1/2 act as TAZ kinases is yet to be determined. Taken together, NDR1/2-mediated phosphorylation of YAP and TAZ may play roles in different cell biological processes that are regulated by NDR1/2. However, except 
for the colon carcinogenesis model discussed above [10], the dependencies of NDR1/2 loss-of-function phenotypes on YAP/TAZ are yet to be investigated experimentally.

\subsubsection{NDR Kinases Functioning Downstream of Hippo and Hippo-Like Kinases}

As already mentioned, Hippo, the fly MST1/2 kinase, can act upstream of Trc and Warts in fly neurons [70]. Specifically, Hippo phosphorylates Trc and Warts on their hydrophobic motif regulatory sites [70]. Very similarly, in mammals MST1/2 can act as regulators of NDR1/2 kinases in centrosome [39], apoptotic [47,50,51] and immune signalling [67] by functioning as hydrophobic motif kinases of NDR1/2 [20]. MST1/2 also phosphorylate LATS1/2 on their respective hydrophobic motif regulatory sites [19], which is important for LATS1/2 activation $[19,86,87]$. In this regard, it is noteworthy that mouse genetics have yet to confirm that MST1/ 2 can act as upstream kinases of LATS1/2 in vivo, while current evidence already suggest that MST1/2 function as upstream kinases of NDR1/2 in vivo in murine T cells [67]. Moreover, ablation of $N d r 1 / 2$ results in intestinal epithelium hyperplasia [10] as observed in Mst1/2 knockout mice [88,89], and $N d r 1 / 2$ double null mouse embryos display multiple phenotypes [17] that are very similar to Mst1/2 double null mouse embryos [90-92]. Thus, it appears that NDR1/2 can function as major effectors of MST1/2 signalling in different biological settings. Nevertheless, one should note that liver overgrowth and tumourigenesis were observed in Lats1/2 and Mst1/2 knockout mice [83,91-93], suggesting that LATS1/2 can also act as major effectors downstream of MST1/2 signalling in vivo.

Intriguingly, NDR1/2 and LATS1/2 are also regulated by other members of the Ste20-like kinase family besides MST1/2. First, MST3 can act as a hydrophobic motif kinase of NDR1/2 [29,94], while MST3 does not seem to function upstream of LATS1/2 [7]. Second, MAP4Ks can function as upstream hydrophobic motif kinases of NDR1/2 [49] and LATS1/2 or Warts in human cells and Drosophila, respectively [7-9]. More specifically, MAP4K4 functions as a hydrophobic kinase of NDR1/2 in osmotic stress signalling [49] and MAP4K4 was identified as a hydrophobic motif kinase of LATS1/2 in an unbiased kinome screen [7]. However, it turned out that Map4k4 deletion in HEK293 cells does not affect YAP phosphorylation [7], hence Guan and colleagues investigated other members of the MAP4Ks family, revealing that several members of the MAP4Ks family can function upstream of LATS1/2 [7]. Nevertheless, in confluence tissue culture conditions residual Ser127 phosphorylation of YAP is still detectable in MM-8KO HEK293 cells (cells with knockouts of the Map4k1/2/3/4/6/7 and $M s t 1 / 2$ genes), suggesting that another upstream kinase of LATS1/2 is yet to be identified [7]. In this regard, one should also consider another possibility, namely that a kinase other than LATS1/2 is phosphorylating YAP on Ser127 in this setting, with NDR1/2 being promising candidates to fulfil this role (see Section 2.3.1 above).

\subsubsection{NDR Kinases Regulated by the MOB1 Scaffold}

In flies, both Trc and Warts are regulated by Hippo, a key member of the Hippo core cassette (see Section 2.3.2 above). Intriguingly, Trc and Warts have been physically and genetically associated with a second key member of the Hippo core cassette. Mats (also known as dMOB1) can interact with Trc and Warts, and is required for Trc and Warts functions in flies [81,95]. Trc, Warts and Mats play important roles in fly wing development with Mats mutant cells displaying phenotypes that were typical of Trc deficiency (i.e., multiple wing hair cells) and of Warts loss-of-function (i.e., tissue overgrowth and increased Yki target expression), strongly suggesting that in flies Mats is required for Trc as well as Warts signalling [81].

In mammalian cells, MOB1, encoded by the distinct Mob1a and Mob1b genes [21], can interact with NDR1/2 and LATS1/2 through a highly conserved NTR domain located proximal to the catalytic domain $[19,23,24,39,56,87,96-100]$, with complex formation between MOB1 and the NDR1/2 or LATS1/2 kinases being essential for kinase activation through the stimulation of auto-phosphorylation $[19,23,24,39,56,87,101,102]$. Significantly, current evidence further suggests that MOB1 is a signal transducer scaffold bridging MST1/2-NDR1/2 [39,47] and MST1/2-LATS1/2 
signalling [6,18], although an alternative model has been published recently [103] that challenges whether Hippo (MST1/2) and Warts (LATS1/2) complex formation is essential for Hippo signalling in fly tissues. More specifically, using a conformation sensor Vrabioiu et al. found that Warts/Mats complex formation is essential for Warts activation, while the stable interaction with Hippo appears to be dispensable. In this context, one should further note that the MST1/2-mediated phosphorylation of MOB1 on Thr12 and Thr35 is required to support the formation of NDR/MOB1 and LATS/MOB1 complexes [104]. In addition, by using membrane-targeted versions of MOB1 it was observed that the recruitment of NDR1 and LATS1 to membrane fractions by MOB1 is sufficient to significantly elevate NDR1 and LATS1 kinase activities [24,87], an effect also observed in fly tissues [105,106].

Recent studies of Mob1a/b knockout mice have revealed that MOB1 loss-of-function results in the most severe deregulation of the Hippo pathway in vivo $[107,108]$, hence suggesting that the MOB1 scaffold represents a central hub of Hippo signalling. However, although MOB1 has clearly been linked to the NDR/Trc and LATS/Warts pathways in mammalian cells and fly tissues (see paragraphs above), the status of NDR1/2 signalling is yet to be studied in Mob1a/1b knockout mice. Therefore, future investigations are warranted to dissect the biological importance of MOB1 interactions with NDR1/2 and LATS1/2 in Hippo signalling.

\subsubsection{Comparison of NDR1/2 and LATS1/2 Regulatory Mechanisms in Hippo Signalling}

As summarised in Section 2.1, the NDR1/2 kinases are regulated by different molecular mechanisms. Significantly, the regulatory mechanisms of LATS1/2 share striking similarities with the regulation of NDR1/2. Specifically, the experimental activation of NDR1/2 and LATS1/2 can be achieved through PP2A inhibition [19,22,25,87], membrane targeting [24,87], and modifications of the hydrophobic motif $[19,25,26]$. In addition, different lines of evidence clearly indicate that the NDR and LATS pathways can be regulated by the same members of the Hippo core cassette. First, both pathways are regulated by MST1/2 (Hippo) in mammalian cells and fly tissue (Section 2.3.2). Second, the NDR and LATS pathways are dependent on the support of MOB1 (Mats) (Section 2.3.3). Moreover, NDR1/2 and LATS1/2 can function as YAP kinases (Section 2.3.1). Therefore, it is very tempting to draw the conclusion that NDR1/2, like LATS1/2, should be considered as members of the Hippo core cassette.

As already summarised above, the NDR and LATS pathways are regulated through molecular mechanisms involving different members of the Hippo core cassette, which influence the phosphorylation status of NDR1/2 and LATS1/2. Interestingly, these similarities can be further extended to additional regulators of NDR1/2 and LATS1/2. For example, the RASSF1A (RAS association domain family 1A) tumour suppressor can trigger apoptotic signalling through MST1/2-mediated activation of LATS1/2 [109-112] and NDR1/2 [47]. Moreover, RASSF6 can inhibit the MST2-mediated activation of NDR1 and LATS2 [113], and both NDR1/2 and LATS1/2 seem to be HSP90 clients $[59,60,114]$. Thus, much is yet to be understood regarding how these diverse molecular players differentiate between the NDR and LATS signalling branches. For instance, besides understanding how additional regulators such as RASSF1A, RASSF6 or HSP90 play their specific roles, we have yet to uncover how MOB1, as a central hub of the Hippo pathway, may differentially interact with NDR1/2 and LATS1/2 and thereby potentially play diverse tumour suppressive roles. In this regard, we will need to define the molecular characteristics and cellular importance of the MOB1 interactions with MST1/2, LATS1/2 and NDR1/2 in Hippo signalling. Recent structural work on MST2 and LATS1 protein fragments in complex with MOB1 [18] together with the structure of the yeast NDR/LATS kinase Cbk1p [115] has started to shed light into the structural biology of the Hippo core cassette. Nevertheless, we have yet to complete our partial structural and molecular understanding of these important processes. In particular the complex formation of MOB1 with NDR1/2 is yet to be understood in the context of Hippo signalling. 


\section{Conclusions and Future Outlook}

Taken together, based on the current evidence, one should consider the mammalian NDR1/2 kinases as novel members of the Hippo core cassette (at least in the context of intestinal epithelial cells). A key remaining question is to investigate in which other cell types and contexts NDR1/2 may function as YAP kinases downstream of Hippo core components such as MST1/2 and MOB1. In this regard, it might also be worth assessing whether Trc functions as a Yki regulator in specific fly tissues. Another interesting question will be to understand whether the regulation of the Hippo core cassette involving NDR1/2 is conserved throughout all eukaryotes. For example, like human NDR1/2 [22,25,116], Trc requires auto- and hydrophobic motif-phosphorylation for functionality [15]. In the filamentous fungus Neurospora crassa, the NDR kinase COT1 is also regulated by interacting with a MOB co-activator that supports T-loop auto-phosphorylation and by hydrophobic motif phosphorylation mediated the Ste20-like kinase POD6 [117]. However, the molecular regulation of the Hippo core cassette is yet to be understood in many other model organisms.

An additional key question should be the investigation of the potential regulatory crosstalk between the NDR and LATS pathways. Intriguingly, fly genetics could show that heterozygosity of a Warts mutant can enhance the Trc dominant negative phenotype in fly wings [81]. Moreover, it has been reported that, in yeast, the counterparts of the NDR and LATS pathways can crosstalk [118]. Thus, it will be interesting to explore any coordination and potential redundancy of NDR $1 / 2$ and LATS1/2 signalling in the Hippo and other important pathways. In this regard, another question is the regulation of transcriptional programmes by NDR1/2. Does NDR1/2 signalling regulate transcriptional regulators, besides YAP? TAZ should be investigated as a possible NDR1/2 substrate (see Section 2.3.1) as well as other transcriptional regulators, since NDR1/2 can interact with FIZ1 (Flt3 interacting zinc finger protein-1) in the nucleus [119]. Therefore, in addition to regulating cellular processes through the phosphorylation of substrates functioning in the cell cycle and other molecular machineries (Tables 1 and 2), the regulation of transcriptional programmes by NDR1/2 signalling may have broader implications than currently appreciated. Consequently, it will be imperative to discriminate between subcellular functions that are dependent and/or independent of NDR1/2 kinase activities.

\section{Abbreviations}

The following abbreviations are used in this manuscript:

$\begin{array}{ll}\text { AGC } & \text { protein kinase A (PKA)/PKG/PKC-like } \\ \text { Cip1 } & \text { cyclin-dependent kinase interacting protein 1 } \\ \text { HP1 } & \text { Heterochromatin protein 1 } \\ \text { HSP90 } & \text { Heat-shock protein 90 } \\ \text { LATS } & \text { large tumour suppressor protein kinase } \\ \text { MAP4K } & \text { Mitogen-activated protein kinase kinase kinase kinase } \\ \text { MICAL-1 } & \text { molecule interacting with CasL-1 } \\ \text { MOB1 } & \text { Mps one binder 1 } \\ \text { MST } & \text { Mammalian serine/threonine sterile 20 (Ste20)-like } \\ \text { NDR } & \text { kinase } \\ \text { Par3 } & \text { Partitioning defective 3 } \\ \text { PLK1 } & \text { Polo-like kinase 1 } \\ \text { PP2A } & \text { protein phosphatase 2A } \\ \text { RASSF } & \text { RAS association domain family } \\ \text { STK } & \text { serine/threonine protein kinase } \\ \text { TAZ } & \text { transcriptional coactivator with PDZ binding motif } \\ \text { TGF } & \text { transforming growth factor } \\ \text { Trc } & \text { Tricornered } \\ \text { ULK1 } & \text { Unc-51 like protein kinase 1 } \\ \text { YAP } & \text { Yes-associated protein } \\ \text { Yki } & \text { Yorkie }\end{array}$


Acknowledgments: We are very grateful to Joanna Lisztwan, Nicolas Tapon, Jacques Camonis and all members of the Hergovich laboratory for their critical review of the manuscript. The work of the Hergovich laboratory is supported by UCL Cancer Research UK centre development funding, and the National Institute for Health Research University College London Hospitals Biomedical Research Centre.

Conflicts of Interest: The author declares no conflict of interest.

\section{References}

1. Yu, F.X.; Guan, K.L. The Hippo pathway: Regulators and regulations. Genes Dev. 2013, 27, 355-371. [CrossRef] [PubMed]

2. Yu, F.X.; Zhao, B.; Guan, K.L. Hippo pathway in organ size control, tissue homeostasis, and cancer. Cell 2015, 163, 811-828. [CrossRef] [PubMed]

3. Hergovich, A.; Stegert, M.R.; Schmitz, D.; Hemmings, B.A. NDR kinases regulate essential cell processes from yeast to humans. Nat. Rev. Mol. Cell Biol. 2006, 7, 253-264. [CrossRef] [PubMed]

4. Hong, W.; Guan, K.L. The YAP and TAZ transcription co-activators: Key downstream effectors of the mammalian Hippo pathway. Semin. Cell Dev. Biol. 2012, 23, 785-793. [CrossRef] [PubMed]

5. Moroishi, T.; Hansen, C.G.; Guan, K.L. The emerging roles of YAP and TAZ in cancer. Nat. Rev. Cancer 2015, 15, 73-79. [CrossRef] [PubMed]

6. Meng, Z.; Moroishi, T.; Guan, K.L. Mechanisms of Hippo pathway regulation. Genes Dev. 2016, 30, 1-17. [CrossRef] [PubMed]

7. Meng, Z.; Moroishi, T.; Mottier-Pavie, V.; Plouffe, S.W.; Hansen, C.G.; Hong, A.W.; Park, H.W.; Mo, J.S.; Lu, W.; Lu, S.; et al. MAP4K family kinases act in parallel to MST1/2 to activate LATS1/2 in the Hippo pathway. Nat. Commun. 2015. [CrossRef] [PubMed]

8. Zheng, Y.; Wang, W.; Liu, B.; Deng, H.; Uster, E.; Pan, D. Identification of happyhour/MAP4K as alternative Hpo/Mst-like kinases in the Hippo kinase cascade. Dev. Cell 2015, 34, 642-655. [CrossRef] [PubMed]

9. Li, Q.; Li, S.; Mana-Capelli, S.; Roth Flach, R.J.; Danai, L.V.; Amcheslavsky, A.; Nie, Y.; Kaneko, S.; Yao, X.; Chen, X.; et al. The conserved misshapen-warts-Yorkie pathway acts in enteroblasts to regulate intestinal stem cells in Drosophila. Dev. Cell 2014, 31, 291-304. [CrossRef] [PubMed]

10. Zhang, L.; Tang, F.; Terracciano, L.; Hynx, D.; Kohler, R.; Bichet, S.; Hess, D.; Cron, P.; Hemmings, B.A.; Hergovich, A.; et al. NDR functions as a physiological YAP1 kinase in the intestinal epithelium. Curr. Biol. 2015, 25, 296-305. [CrossRef] [PubMed]

11. Johnston, L.H.; Eberly, S.L.; Chapman, J.W.; Araki, H.; Sugino, A. The product of the saccharomyces cerevisiae cell cycle gene DBF2 has homology with protein kinases and is periodically expressed in the cell cycle. Mol. Cell Biol. 1990, 10, 1358-1366. [CrossRef] [PubMed]

12. Yarden, O.; Plamann, M.; Ebbole, D.J.; Yanofsky, C. Cot-1, a gene required for hyphal elongation in neurospora crassa, encodes a protein kinase. Embo. J. 1992, 11, 2159-2166. [PubMed]

13. Millward, T.; Cron, P.; Hemmings, B.A. Molecular cloning and characterization of a conserved nuclear serine(threonine) protein kinase. Proc. Natl. Acad. Sci. USA 1995, 92, 5022-5026. [CrossRef] [PubMed]

14. Geng, W.; He, B.; Wang, M.; Adler, P.N. The tricornered gene, which is required for the integrity of epidermal cell extensions, encodes the Drosophila nuclear DBF2-related kinase. Genetics 2000, 156, 1817-1828. [PubMed]

15. He, Y.; Fang, X.; Emoto, K.; Jan, Y.N.; Adler, P.N. The tricornered Ser/Thr protein kinase is regulated by phosphorylation and interacts with furry during Drosophila wing hair development. Mol. Biol. Cell 2005, 16, 689-700. [CrossRef] [PubMed]

16. Ma, J.; Benz, C.; Grimaldi, R.; Stockdale, C.; Wyatt, P.; Frearson, J.; Hammarton, T.C. Nuclear DBF-2-related kinases are essential regulators of cytokinesis in bloodstream stage Trypanosoma brucei. J. Biol. Chem. 2010, 285, 15356-15368. [CrossRef] [PubMed]

17. Schmitz-Rohmer, D.; Probst, S.; Yang, Z.Z.; Laurent, F.; Stadler, M.B.; Zuniga, A.; Zeller, R.; Hynx, D.; Hemmings, B.A.; Hergovich, A. NDR kinases are essential for somitogenesis and cardiac looping during mouse embryonic development. PLoS ONE 2015, 10, e0136566. [CrossRef] [PubMed]

18. Ni, L.; Zheng, Y.; Hara, M.; Pan, D.; Luo, X. Structural basis for Mob1-dependent activation of the core Mst-Lats kinase cascade in Hippo signaling. Genes Dev. 2015, 29, 1416-1431. [CrossRef] [PubMed]

19. Hoa, L.; Kulaberoglu, Y.; Gundogdu, R.; Cook, D.; Mavis, M.; Gomez, M.; Gomez, V.; Hergovich, A. The characterisation of LATS2 kinase regulation in Hippo-YAP signalling. Cell Signal. 2016, 28, 488-497. [CrossRef] [PubMed] 
20. Hergovich, A. Regulation and functions of mammalian LATS/NDR kinases: Looking beyond canonical Hippo signalling. Cell Biosci. 2013. [CrossRef] [PubMed]

21. Hergovich, A. Mob control: Reviewing a conserved family of kinase regulators. Cell Signal. 2011, 23, 1433-1440. [CrossRef] [PubMed]

22. Millward, T.A.; Hess, D.; Hemmings, B.A. NDR protein kinase is regulated by phosphorylation on two conserved sequence motifs. J. Biol. Chem. 1999, 274, 33847-33850. [CrossRef] [PubMed]

23. Bichsel, S.J.; Tamaskovic, R.; Stegert, M.R.; Hemmings, B.A. Mechanism of activation of NDR (nuclear DBF2-related) protein kinase by the hMOB1 protein. J. Biol. Chem. 2004, 279, 35228-35235. [CrossRef] [PubMed]

24. Hergovich, A.; Bichsel, S.J.; Hemmings, B.A. Human NDR kinases are rapidly activated by MOB proteins through recruitment to the plasma membrane and phosphorylation. Mol. Cell Biol. 2005, 25, 8259-8272. [CrossRef] [PubMed]

25. Stegert, M.R.; Tamaskovic, R.; Bichsel, S.J.; Hergovich, A.; Hemmings, B.A. Regulation of NDR2 protein kinase by multi-site phosphorylation and the s100b calcium-binding protein. J. Biol. Chem. 2004, 279, 23806-23812. [CrossRef] [PubMed]

26. Cook, D.; Hoa, L.Y.; Gomez, V.; Gomez, M.; Hergovich, A. Constitutively active NDR1-PIF kinase functions independent of MST1 and hMOB1 signalling. Cell Signal. 2014, 26, 1657-1667. [CrossRef] [PubMed]

27. Takeuchi, T.; Inoue, S.; Yokosawa, H. Identification and Herc5-mediated ISGylation of novel target proteins. Biochem. Biophys. Res. Commun. 2006, 348, 473-477. [CrossRef] [PubMed]

28. Cornils, H.; Kohler, R.S.; Hergovich, A.; Hemmings, B.A. Downstream of human NDR kinases: Impacting on c-myc and p21 protein stability to control cell cycle progression. Cell Cycle 2011, 10, 1897-1904. [CrossRef] [PubMed]

29. Cornils, H.; Kohler, R.S.; Hergovich, A.; Hemmings, B.A. Human NDR kinases control G(1)/S cell cycle transition by directly regulating p21 stability. Mol. Cell. Biol. 2011, 31, 1382-1395. [CrossRef] [PubMed]

30. Bisikirska, B.C.; Adam, S.J.; Alvarez, M.J.; Rajbhandari, P.; Cox, R.; Lefebvre, C.; Wang, K.; Rieckhof, G.E.; Felsher, D.W.; Califano, A. STK38 is a critical upstream regulator of myc's oncogenic activity in human B-cell lymphoma. Oncogene 2013, 32, 5283-5291. [CrossRef] [PubMed]

31. Wang, K.; Saito, M.; Bisikirska, B.C.; Alvarez, M.J.; Lim, W.K.; Rajbhandari, P.; Shen, Q.; Nemenman, I.; Basso, K.; Margolin, A.A.; et al. Genome-wide identification of post-translational modulators of transcription factor activity in human B cells. Nat. Biotechnol. 2009, 27, 829-839. [CrossRef] [PubMed]

32. Du, Z.; Tong, X.; Ye, X. Cyclin D1 promotes cell cycle progression through enhancing NDR1/2 kinase activity independent of cyclin-dependent kinase 4. J. Biol. Chem. 2013, 288, 26678-26687. [CrossRef] [PubMed]

33. Pot, I.; Patel, S.; Deng, L.; Chandhoke, A.S.; Zhang, C.; Bonni, A.; Bonni, S. Identification of a novel link between the protein kinase NDR1 and TGF $\beta$ signaling in epithelial cells. PLoS ONE 2013, 8, e67178. [CrossRef] [PubMed]

34. Oh, H.J.; Kim, M.J.; Song, S.J.; Kim, T.; Lee, D.; Kwon, S.H.; Choi, E.J.; Lim, D.S. MST1 limits the kinase activity of aurora $\mathrm{b}$ to promote stable kinetochore-microtubule attachment. Curr. Biol. 2010, 20, 416-422. [CrossRef] [PubMed]

35. Chiba, S.; Ikeda, M.; Katsunuma, K.; Ohashi, K.; Mizuno, K. MST2- and furry-mediated activation of NDR1 kinase is critical for precise alignment of mitotic chromosomes. Curr. Biol. 2009, 19, 675-681. [CrossRef] [PubMed]

36. Chakraborty, A.; Prasanth, K.V.; Prasanth, S.G. Dynamic phosphorylation of HP1 $\alpha$ regulates mitotic progression in human cells. Nat. Commun. 2014. [CrossRef] [PubMed]

37. Yan, M.; Chu, L.; Qin, B.; Wang, Z.; Liu, X.; Jin, C.; Zhang, G.; Gomez, M.; Hergovich, A.; Chen, Z.; et al. Regulation of NDR1 activity by PLK1 ensures proper spindle orientation in mitosis. Sci. Rep. 2015. [CrossRef] [PubMed]

38. Hergovich, A.; Lamla, S.; Nigg, E.A.; Hemmings, B.A. Centrosome-associated NDR kinase regulates centrosome duplication. Mol. Cell 2007, 25, 625-634. [CrossRef] [PubMed]

39. Hergovich, A.; Kohler, R.S.; Schmitz, D.; Vichalkovski, A.; Cornils, H.; Hemmings, B.A. The MST1 and hMOB1 tumor suppressors control human centrosome duplication by regulating NDR kinase phosphorylation. Curr. Biol. 2009, 19, 1692-1702. [CrossRef] [PubMed] 
40. Chiba, S.; Amagai, Y.; Homma, Y.; Fukuda, M.; Mizuno, K. NDR2-mediated Rabin8 phosphorylation is crucial for ciliogenesis by switching binding specificity from phosphatidylserine to Sec15. Embo. J. 2013, 32, 874-885. [CrossRef] [PubMed]

41. Goldstein, O.; Kukekova, A.V.; Aguirre, G.D.; Acland, G.M. Exonic SINE insertion in STK38L causes canine early retinal degeneration (erd). Genomics 2010, 96, 362-368. [CrossRef] [PubMed]

42. Berta, A.I.; Boesze-Battaglia, K.; Genini, S.; Goldstein, O.; O’Brien, P.J.; Szel, A.; Acland, G.M.; Beltran, W.A.; Aguirre, G.D. Photoreceptor cell death, proliferation and formation of hybrid rod/S-cone photoreceptors in the degenerating STK38L mutant retina. PLoS ONE 2011, 6, e24074. [CrossRef] [PubMed]

43. Hilgendorf, K.I.; Johnson, C.T.; Jackson, P.K. The primary cilium as a cellular receiver: Organizing ciliary GPCR signaling. Curr. Opin. Cell Biol. 2016, 39, 84-92. [CrossRef] [PubMed]

44. Mukhopadhyay, S.; Rohatgi, R. G-protein-coupled receptors, hedgehog signaling and primary cilia. Semin. Cell Dev. Biol. 2014, 33, 63-72. [CrossRef] [PubMed]

45. Pampliega, O.; Cuervo, A.M. Autophagy and primary cilia: Dual interplay. Curr. Opin. Cell Biol. 2016, 39, 1-7. [CrossRef] [PubMed]

46. Kim, S.; Dynlacht, B.D. Assembling a primary cilium. Curr. Opin. Cell Biol. 2013, 25, 506-511. [CrossRef] [PubMed]

47. Vichalkovski, A.; Gresko, E.; Cornils, H.; Hergovich, A.; Schmitz, D.; Hemmings, B.A. NDR kinase is activated by RASSF1A/MST1 in response to fas receptor stimulation and promotes apoptosis. Curr. Biol. 2008, 18, 1889-1895. [CrossRef] [PubMed]

48. Joffre, C.; Dupont, N.; Hoa, L.; Gomez, V.; Pardo, R.; Goncalves-Pimentel, C.; Achard, P.; Bettoun, A.; Meunier, B.; Bauvy, C.; et al. The pro-apoptotic STK38 kinase is a new beclin1 partner positively regulating autophagy. Curr. Biol. 2015, 25, 2479-2492. [CrossRef] [PubMed]

49. Selimoglu, R.; Bettoun, A.; Joffre, C.; Meunier, B.; Parrini, M.C.; Fesquet, D.; Formstecher, E.; Cascone, I.; Hergovich, A.; Camonis, J. RalA GTPase and MAP4K4 function through NDR1 activation in stress response and apoptotic signaling. Available online: http://www.heraldopenaccess.us/fulltext/Cell-Biology-\&-CellMetabolism/RalA-GTPase-and-MAP4K4-Function-through-NDR1-Activation-in-Stress-Response-andApoptotic-Signaling.php (accessed on 18 August 2014).

50. Loria, R.; Bon, G.; Perotti, V.; Gallo, E.; Bersani, I.; Baldassari, P.; Porru, M.; Leonetti, C.; Di Carlo, S.; Visca, P.; et al. Sema6A and Mical1 control cell growth and survival of BRAFV600E human melanoma cells. Oncotarget 2015, 6, 2779-2793. [CrossRef] [PubMed]

51. Zhou, Y.; Adolfs, Y.; Pijnappel, W.W.; Fuller, S.J.; Van der Schors, R.C.; Li, K.W.; Sugden, P.H.; Smit, A.B.; Hergovich, A.; Pasterkamp, R.J. MICAL-1 is a negative regulator of MST-NDR kinase signaling and apoptosis. Mol. Cell Biol. 2011, 31, 3603-3615. [CrossRef] [PubMed]

52. Cornils, H.; Stegert, M.R.; Hergovich, A.; Hynx, D.; Schmitz, D.; Dirnhofer, S.; Hemmings, B.A. Ablation of the kinase NDR1 predisposes mice to the development of T cell lymphoma. Sci. Signal. 2010. [CrossRef] [PubMed]

53. Fuller, S.J.; Pikkarainen, S.; Tham el, L.; Cullingford, T.E.; Molkentin, J.D.; Cornils, H.; Hergovich, A.; Hemmings, B.A.; Clerk, A.; Sugden, P.H. Nuclear Dbf2-related protein kinases (NDRs) in isolated cardiac myocytes and the myocardium: Activation by cellular stresses and by phosphoprotein serine-/ threonine-phosphatase inhibitors. Cell Signal. 2008, 20, 1564-1577. [CrossRef] [PubMed]

54. Joffre, C.; Codogno, P.; Fanto, M.; Hergovich, A.; Camonis, J. STK38 at the crossroad between autophagy and apoptosis. Autophagy 2016, 12, 594-595. [CrossRef] [PubMed]

55. Wu, Z.; Sawada, T.; Shiba, K.; Liu, S.; Kanao, T.; Takahashi, R.; Hattori, N.; Imai, Y.; Lu, B. Tricornered/NDR kinase signaling mediates pink1-directed mitochondrial quality control and tissue maintenance. Genes Dev. 2013, 27, 157-162. [CrossRef] [PubMed]

56. Kohler, R.S.; Schmitz, D.; Cornils, H.; Hemmings, B.A.; Hergovich, A. Differential NDR/LATS interactions with the human MOB family reveal a negative role for human MOB2 in the regulation of human NDR kinases. Mol. Cell Biol. 2010, 30, 4507-4520. [CrossRef] [PubMed]

57. Gomez, V.; Gundogdu, R.; Gomez, M.; Hoa, L.; Panchal, N.; O’Driscoll, M.; Hergovich, A. Regulation of DNA damage responses and cell cycle progression by hMOB2. Cell Signal. 2015, 27, 326-339. [CrossRef] [PubMed] 
58. Park, J.M.; Choi, J.Y.; Yi, J.M.; Chung, J.W.; Leem, S.H.; Koh, S.S.; Kang, T.H. NDR1 modulates the UV-induced DNA-damage checkpoint and nucleotide excision repair. Biochem. Biophys. Res. Commun. 2015, 461, 543-548. [CrossRef] [PubMed]

59. Enomoto, A.; Fukasawa, T.; Takamatsu, N.; Ito, M.; Morita, A.; Hosoi, Y.; Miyagawa, K. The HSP90 inhibitor 17-allylamino-17-demethoxygeldanamycin modulates radiosensitivity by downregulating serine/threonine kinase 38 via Sp1 inhibition. Eur. J. Cancer. 2013, 49, 3547-3558. [CrossRef] [PubMed]

60. Taipale, M.; Krykbaeva, I.; Koeva, M.; Kayatekin, C.; Westover, K.D.; Karras, G.I.; Lindquist, S. Quantitative analysis of HSP90-client interactions reveals principles of substrate recognition. Cell 2012, 150, 987-1001. [CrossRef] [PubMed]

61. Fukasawa, T.; Enomoto, A.; Miyagawa, K. Serine-Threonine Kinase 38 regulates CDC25A stability and the DNA damage-induced G2/M checkpoint. Cell Signal. 2015, 27, 1569-1575. [CrossRef] [PubMed]

62. Jin, J.; Shirogane, T.; Xu, L.; Nalepa, G.; Qin, J.; Elledge, S.J.; Harper, J.W. SCF $\beta$-TRCP links Chk1 signaling to degradation of the Cdc25A protein phosphatase. Genes Dev. 2003, 17, 3062-3074. [CrossRef] [PubMed]

63. Reinhardt, H.C.; Yaffe, M.B. Phospho-Ser/Thr-binding domains: Navigating the cell cycle and DNA damage response. Nat. Rev. Mol. Cell Biol. 2013, 14, 563-580. [CrossRef] [PubMed]

64. Wang, H.; Zhang, X.; Teng, L.; Legerski, R.J. DNA damage checkpoint recovery and cancer development. Exp. Cell Res. 2015, 334, 350-358. [CrossRef] [PubMed]

65. Devroe, E.; Silver, P.A.; Engelman, A. HIV-1 incorporates and proteolytically processes human NDR1 and NDR2 serine-threonine kinases. Virology 2005, 331, 181-189. [CrossRef] [PubMed]

66. Wen, M.; Ma, X.; Cheng, H.; Jiang, W.; Xu, X.; Zhang, Y.; Guo, Z.; Yu, Y.; Xu, H.; Qian, C.; et al. Stk38 protein kinase preferentially inhibits TLR9-activated inflammatory responses by promoting MEKK2 ubiquitination in macrophages. Nat. Commun. 2015. [CrossRef] [PubMed]

67. Tang, F.; Gill, J.; Ficht, X.; Barthlott, T.; Cornils, H.; Schmitz-Rohmer, D.; Hynx, D.; Zhou, D.; Zhang, L.; Xue, G.; et al. The kinases NDR1/2 act downstream of the Hippo homolog MST1 to mediate both egress of thymocytes from the thymus and lymphocyte motility. Sci. Signal. 2015. [CrossRef] [PubMed]

68. Emoto, K. The growing role of the Hippo--NDR kinase signalling in neuronal development and disease. J. Biochem. 2011, 150, 133-141. [CrossRef] [PubMed]

69. Emoto, K.; He, Y.; Ye, B.; Grueber, W.B.; Adler, P.N.; Jan, L.Y.; Jan, Y.N. Control of dendritic branching and tiling by the tricornered-kinase/furry signaling pathway in Drosophila sensory neurons. Cell 2004, 119, 245-256. [CrossRef] [PubMed]

70. Emoto, K.; Parrish, J.Z.; Jan, L.Y.; Jan, Y.N. The tumour suppressor Hippo acts with the NDR kinases in dendritic tiling and maintenance. Nature 2006, 443, 210-213. [CrossRef] [PubMed]

71. Koike-Kumagai, M.; Yasunaga, K.; Morikawa, R.; Kanamori, T.; Emoto, K. The target of rapamycin complex 2 controls dendritic tiling of Drosophila sensory neurons through the tricornered kinase signalling pathway. Embo. J. 2009, 28, 3879-3892. [CrossRef] [PubMed]

72. Ultanir, S.K.; Hertz, N.T.; Li, G.; Ge, W.P.; Burlingame, A.L.; Pleasure, S.J.; Shokat, K.M.; Jan, L.Y.; Jan, Y.N. Chemical genetic identification of NDR1/2 kinase substrates AAK1 and Rabin8 uncovers their roles in dendrite arborization and spine development. Neuron 2012, 73, 1127-1142. [CrossRef] [PubMed]

73. Yang, R.; Kong, E.; Jin, J.; Hergovich, A.; Puschel, A.W. Rassf5 and NDR kinases regulate neuronal polarity through Par3 phosphorylation in a novel pathway. J. Cell Sci. 2014, 127, 3463-3476. [CrossRef] [PubMed]

74. Rehberg, K.; Kliche, S.; Madencioglu, D.A.; Thiere, M.; Muller, B.; Meineke, B.M.; Freund, C.; Budinger, E.; Stork, O. The serine/threonine kinase NDR2 controls integrin trafficking and integrin-dependent neurite growth. J. Neurosci. 2014, 34, 5342-5354. [CrossRef] [PubMed]

75. Du, Y.; Ge, M.M.; Xue, W.; Yang, Q.Q.; Wang, S.; Xu, Y.; Wang, H.L. Chronic lead exposure and mixed factors of genderxagexbrain regions interactions on dendrite growth, spine maturity and NDR kinase. PLoS ONE 2015, 10, e0138112. [CrossRef] [PubMed]

76. Zhao, B.; Wei, X.; Li, W.; Udan, R.S.; Yang, Q.; Kim, J.; Xie, J.; Ikenoue, T.; Yu, J.; Li, L.; et al. Inactivation of YAP oncoprotein by the Hippo pathway is involved in cell contact inhibition and tissue growth control. Genes Dev. 2007, 21, 2747-2761. [CrossRef] [PubMed]

77. Dong, J.; Feldmann, G.; Huang, J.; Wu, S.; Zhang, N.; Comerford, S.A.; Gayyed, M.F.; Anders, R.A.; Maitra, A.; Pan, D. Elucidation of a universal size-control mechanism in Drosophila and mammals. Cell 2007, 130, 1120-1133. [CrossRef] [PubMed] 
78. Oka, T.; Mazack, V.; Sudol, M. Mst2 and Lats kinases regulate apoptotic function of Yes kinase-associated protein (Yap). J. Biol. Chem. 2008, 283, 27534-27546. [CrossRef] [PubMed]

79. Melixetian, M.; Klein, D.K.; Sorensen, C.S.; Helin, K. NEK11 regulates CDC25A degradation and the IR-induced G2/M checkpoint. Nat. Cell Biol. 2009, 11, 1247-1253. [CrossRef] [PubMed]

80. Fang, X.; Adler, P.N. Regulation of cell shape, wing hair initiation and the actin cytoskeleton by Trc/Fry and Wts/Mats complexes. Dev. Biol. 2010, 341, 360-374. [CrossRef] [PubMed]

81. He, Y.; Emoto, K.; Fang, X.; Ren, N.; Tian, X.; Jan, Y.N.; Adler, P.N. Drosophila Mob family proteins interact with the related tricornered (Trc) and warts (Wts) kinases. Mol. Biol. Cell 2005, 16, 4139-4152. [CrossRef] [PubMed]

82. Hao, Y.; Chun, A.; Cheung, K.; Rashidi, B.; Yang, X. Tumor suppressor LATS1 is a negative regulator of oncogene YAP. J. Biol. Chem. 2008, 283, 5496-5509. [CrossRef] [PubMed]

83. Chen, Q.; Zhang, N.; Xie, R.; Wang, W.; Cai, J.; Choi, K.S.; David, K.K.; Huang, B.; Yabuta, N.; Nojima, H.; et al . Homeostatic control of Hippo signaling activity revealed by an endogenous activating mutation in YAP. Genes Dev. 2015, 29, 1285-1297. [CrossRef] [PubMed]

84. Mo, J.S.; Meng, Z.; Kim, Y.C.; Park, H.W.; Hansen, C.G.; Kim, S.; Lim, D.S.; Guan, K.L. Cellular energy stress induces AMPK-mediated regulation of YAP and the Hippo pathway. Nat. Cell. Biol. 2015, 17, 500-510. [CrossRef] [PubMed]

85. Lin, C.W.; Chang, Y.L.; Chang, Y.C.; Lin, J.C.; Chen, C.C.; Pan, S.H.; Wu, C.T.; Chen, H.Y.; Yang, S.C.; Hong, T.M.; et al. MicroRNA-135b promotes lung cancer metastasis by regulating multiple targets in the Hippo pathway and LZTS1. Nat. Commun. 2013. [CrossRef] [PubMed]

86. Chan, E.H.; Nousiainen, M.; Chalamalasetty, R.B.; Schafer, A.; Nigg, E.A.; Sillje, H.H. The Ste20-like kinase Mst2 activates the human large tumor suppressor kinase Lats1. Oncogene 2005, 24, 2076-2086. [CrossRef] [PubMed]

87. Hergovich, A.; Schmitz, D.; Hemmings, B.A. The human tumour suppressor LATS1 is activated by human MOB1 at the membrane. Biochem. Biophys. Res. Commun. 2006, 345, 50-58. [CrossRef] [PubMed]

88. Cai, J.; Zhang, N.; Zheng, Y.; de Wilde, R.F.; Maitra, A.; Pan, D. The Hippo signaling pathway restricts the oncogenic potential of an intestinal regeneration program. Genes Dev. 2010, 24, 2383-2388. [CrossRef] [PubMed]

89. Zhou, D.; Zhang, Y.; Wu, H.; Barry, E.; Yin, Y.; Lawrence, E.; Dawson, D.; Willis, J.E.; Markowitz, S.D.; Camargo, F.D.; et al. Mst1 and Mst2 protein kinases restrain intestinal stem cell proliferation and colonic tumorigenesis by inhibition of Yes-associated protein (Yap) overabundance. Proc. Natl. Acad. Sci. USA 2011. [CrossRef] [PubMed]

90. Oh, S.; Lee, D.; Kim, T.; Kim, T.S.; Oh, H.J.; Hwang, C.Y.; Kong, Y.Y.; Kwon, K.S.; Lim, D.S. Crucial role for Mst1 and Mst2 kinases in early embryonic development of the mouse. Mol. Cell. Biol. 2009, 29, 6309-6320. [CrossRef] [PubMed]

91. Song, H.; Mak, K.K.; Topol, L.; Yun, K.; Hu, J.; Garrett, L.; Chen, Y.; Park, O.; Chang, J.; Simpson, R.M.; et al. Mammalian Mst1 and Mst2 kinases play essential roles in organ size control and tumor suppression. Proc. Natl. Acad. Sci. USA 2010, 107, 1431-1436. [CrossRef] [PubMed]

92. Zhou, D.; Conrad, C.; Xia, F.; Park, J.S.; Payer, B.; Yin, Y.; Lauwers, G.Y.; Thasler, W.; Lee, J.T.; Avruch, J.; et al. Mst1 and Mst2 maintain hepatocyte quiescence and suppress hepatocellular carcinoma development through inactivation of the Yap1 oncogene. Cancer Cell 2009, 16, 425-438. [CrossRef] [PubMed]

93. Lu, L.; Li, Y.; Kim, S.M.; Bossuyt, W.; Liu, P.; Qiu, Q.; Wang, Y.; Halder, G.; Finegold, M.J.; Lee, J.S.; et al. Hippo signaling is a potent in vivo growth and tumor suppressor pathway in the mammalian liver. Proc. Natl. Acad. Sci. USA 2010, 107, 1437-1442. [CrossRef] [PubMed]

94. Stegert, M.R.; Hergovich, A.; Tamaskovic, R.; Bichsel, S.J.; Hemmings, B.A. Regulation of NDR protein kinase by hydrophobic motif phosphorylation mediated by the mammalian Ste20-like kinase MST3. Mol. Cell Biol. 2005, 25, 11019-11029. [CrossRef] [PubMed]

95. Lai, Z.C.; Wei, X.; Shimizu, T.; Ramos, E.; Rohrbaugh, M.; Nikolaidis, N.; Ho, L.L.; Li, Y. Control of cell proliferation and apoptosis by mob as tumor suppressor, mats. Cell 2005, 120, 675-685. [CrossRef] [PubMed]

96. Devroe, E.; Erdjument-Bromage, H.; Tempst, P.; Silver, P.A. Human mob proteins regulate the NDR1 and NDR2 serine-threonine kinases. J. Biol. Chem. 2004, 279, 24444-24451. [CrossRef] [PubMed]

97. Bothos, J.; Tuttle, R.L.; Ottey, M.; Luca, F.C.; Halazonetis, T.D. Human LATS1 is a mitotic exit network kinase. Cancer Res. 2005, 65, 6568-6575. [CrossRef] [PubMed] 
98. Yabuta, N.; Okada, N.; Ito, A.; Hosomi, T.; Nishihara, S.; Sasayama, Y.; Fujimori, A.; Okuzaki, D.; Zhao, H.; Ikawa, M.; et al. Lats2 is an essential mitotic regulator required for the coordination of cell division. J. Biol. Chem. 2007, 282, 19259-19271. [CrossRef] [PubMed]

99. Ponchon, L.; Dumas, C.; Kajava, A.V.; Fesquet, D.; Padilla, A. NMR solution structure of Mob1, a mitotic exit network protein and its interaction with an NDR kinase peptide. J. Mol. Biol. 2004, 337, 167-182. [CrossRef] [PubMed]

100. Stavridi, E.S.; Harris, K.G.; Huyen, Y.; Bothos, J.; Verwoerd, P.M.; Stayrook, S.E.; Pavletich, N.P.; Jeffrey, P.D.; Luca, F.C. Crystal structure of a human Mob1 protein: Toward understanding Mob-regulated cell cycle pathways. Structure 2003, 11, 1163-1170. [CrossRef]

101. Kim, M.; Lee, S.; Kuninaka, S.; Saya, H.; Lee, H.; Lim, D.S. cAMP/PKA signalling reinforces the LATS-YAP pathway to fully suppress YAP in response to actin cytoskeletal changes. Embo. J. 2013, 32, 1543-1555. [CrossRef] [PubMed]

102. Wei, X.; Shimizu, T.; Lai, Z.C. Mob as tumor suppressor is activated by Hippo kinase for growth inhibition in Drosophila. Embo. J. 2007, 26, 1772-1781. [CrossRef] [PubMed]

103. Vrabioiu, A.M.; Struhl, G. Fat/dachsous signaling promotes Drosophila wing growth by regulating the conformational state of the NDR kinase warts. Dev. Cell 2015, 35, 737-749. [CrossRef] [PubMed]

104. Praskova, M.; Xia, F.; Avruch, J. MOBKL1A/MOBKL1B phosphorylation by MST1 and MST2 inhibits cell proliferation. Curr. Biol. 2008, 18, 311-321. [CrossRef] [PubMed]

105. Yin, F.; Yu, J.; Zheng, Y.; Chen, Q.; Zhang, N.; Pan, D. Spatial organization of Hippo signaling at the plasma membrane mediated by the tumor suppressor Merlin/NF2. Cell 2013, 154, 1342-1355. [CrossRef] [PubMed]

106. Ho, L.L.; Wei, X.; Shimizu, T.; Lai, Z.C. Mob as tumor suppressor is activated at the cell membrane to control tissue growth and organ size in Drosophila. Dev. Biol. 2010, 337, 274-283. [CrossRef] [PubMed]

107. Nishio, M.; Sugimachi, K.; Goto, H.; Wang, J.; Morikawa, T.; Miyachi, Y.; Takano, Y.; Hikasa, H.; Itoh, T.; Suzuki, S.O.; et al. Dysregulated YAP1/TAZ and TGF- $\beta$ signaling mediate hepatocarcinogenesis in Mob1a/1b-deficient mice. Proc. Natl. Acad. Sci. USA 2016, 113, 71-80. [CrossRef] [PubMed]

108. Nishio, M.; Hamada, K.; Kawahara, K.; Sasaki, M.; Noguchi, F.; Chiba, S.; Mizuno, K.; Suzuki, S.O.; Dong, Y.; Tokuda, M.; et al. Cancer susceptibility and embryonic lethality in Mob1a/1b double-mutant mice. J. Clin. Investig. 2012, 122, 4505-4518. [CrossRef] [PubMed]

109. Guo, C.; Zhang, X.; Pfeifer, G.P. The tumor suppressor RASSF1A prevents dephosphorylation of the mammalian STE20-like kinases MST1 and MST2. J. Biol. Chem. 2011, 286, 6253-6261. [CrossRef] [PubMed]

110. Matallanas, D.; Romano, D.; Yee, K.; Meissl, K.; Kucerova, L.; Piazzolla, D.; Baccarini, M.; Vass, J.K.; Kolch, W.; O'Neill, E. RASSF1A elicits apoptosis through an MST2 pathway directing proapoptotic transcription by the p73 tumor suppressor protein. Mol. Cell 2007, 27, 962-975. [CrossRef] [PubMed]

111. Oh, H.J.; Lee, K.K.; Song, S.J.; Jin, M.S.; Song, M.S.; Lee, J.H.; Im, C.R.; Lee, J.O.; Yonehara, S.; Lim, D.S. Role of the tumor suppressor RASSF1A in MST1-mediated apoptosis. Cancer Res. 2006, 66, 2562-2569. [CrossRef] [PubMed]

112. Praskova, M.; Khoklatchev, A.; Ortiz-Vega, S.; Avruch, J. Regulation of the MST1 kinase by autophosphorylation, by the growth inhibitory proteins, RASSF1 and NORE1, and by Ras. Biochem. J. 2004, 381, 453-462. [CrossRef] [PubMed]

113. Ikeda, M.; Kawata, A.; Nishikawa, M.; Tateishi, Y.; Yamaguchi, M.; Nakagawa, K.; Hirabayashi, S.; Bao, Y.; Hidaka, S.; Hirata, Y.; et al. Hippo pathway-dependent and -independent roles of RASSF6. Sci. Signal. 2009. [CrossRef] [PubMed]

114. Huntoon, C.J.; Nye, M.D.; Geng, L.; Peterson, K.L.; Flatten, K.S.; Haluska, P.; Kaufmann, S.H.; Karnitz, L.M. Heat shock protein 90 inhibition depletes LATS1 and LATS2, two regulators of the mammalian Hippo tumor suppressor pathway. Cancer Res. 2010, 70, 8642-8650. [CrossRef] [PubMed]

115. Gogl, G.; Schneider, K.D.; Yeh, B.J.; Alam, N.; Nguyen Ba, A.N.; Moses, A.M.; Hetenyi, C.; Remenyi, A.; Weiss, E.L. The structure of an NDR/LATS kinase-Mob complex reveals a novel kinase-coactivator system and substrate docking mechanism. PLoS Biol. 2015. [CrossRef] [PubMed]

116. Tamaskovic, R.; Bichsel, S.J.; Rogniaux, H.; Stegert, M.R.; Hemmings, B.A. Mechanism of Ca ${ }^{2+}$-mediated regulation of NDR protein kinase through autophosphorylation and phosphorylation by an upstream kinase. J. Biol. Chem. 2003, 278, 6710-6718. [CrossRef] [PubMed] 
117. Maerz, S.; Dettmann, A.; Seiler, S. Hydrophobic motif phosphorylation coordinates activity and polar localization of the neurospora crassa nuclear Dbf2-related kinase COT1. Mol. Cell. Biol. 2012, 32, $2083-2098$. [CrossRef] [PubMed]

118. Gupta, S.; Mana-Capelli, S.; McLean, J.R.; Chen, C.T.; Ray, S.; Gould, K.L.; McCollum, D. Identification of sin pathway targets reveals mechanisms of crosstalk between NDR kinase pathways. Curr. Biol. 2013, 23, 333-338. [CrossRef] [PubMed]

119. Lariviere, N.; Law, J.; Trinkle-Mulcahy, L. Dissection of a novel autocrine signaling pathway via quantitative secretome and interactome mapping. J. Proteome Res. 2014, 13, 3432-3443. [CrossRef] [PubMed]

(C) 2016 by the author; licensee MDPI, Basel, Switzerland. This article is an open access article distributed under the terms and conditions of the Creative Commons Attribution (CC-BY) license (http://creativecommons.org/licenses/by/4.0/). 